\title{
The New Line Copenhagen-Ringsted: the benefits from EU railway benchmarking
}

\author{
I. Trabo ${ }^{1,2}$, A. Landex ${ }^{2}$, J. E. Schneider-Tilli ${ }^{1}$ \& O. A. Nielsen ${ }^{2}$ \\ ${ }^{1}$ Banedanmark (Rail Net Denmark), Copenhagen, Denmark \\ ${ }^{2}$ Technical University of Denmark, Lyngby, Denmark
}

\begin{abstract}
Companies in many different business areas face unexpected budget overruns when carrying out large-scale projects. Usually this happens because of underestimation of actual costs during budgeting. That is why it is important to have specific knowledge of the market situation, not only in one specific country, but also outside the country's borders. It helps, for example, to find relevant information about construction materials to lower prices and reducing a project's planned costs by several per cent. The same is true of technology and the companies involved in the construction of the project. "The New Line Copenhagen-Ringsted" project being developed by Rail Net Denmark will be the first high-speed railway line in Denmark with a total budget of EUR 1.10 billion. The focus is on avoiding a budget overrun and on therefore looking for ways of reducing project costs. We have conducted a benchmark study of other similar high-speed railway lines in Europe. France, Italy, and Spain have long and productive experience in constructing and operating high-speed railway lines. Investigating their best practices brings valuable knowledge to the project. This paper presents the data we gathered and our results, which will be useful for other infrastructure managers. Infrastructure managers will be able to make their own benchmarks to come to conclusions about how they can avoid budget overruns for future projects.
\end{abstract}

Keywords: railway, benchmarking, cost drivers, budget overruns, unit costs.

\section{Introduction}

The construction of the new high-speed lines requires long planning procedures, skilled and experienced staff, and huge investments. The final investment costs 
for European railway projects vary between EUR 12 and 45 million [1] per kilometre, depending on the alignment allocation, amount of physical structures, and difficulties during construction. When planning the budget for new lines, making cost-benefit analysis and forecasting future profit, it is always difficult to predict the exact financial outcome of projects. Many real-life examples of large infrastructure projects show that the initial costs were underestimated, and the final costs include a large percentage of cost overruns. Many researchers are paying attention to this problem and trying to find explanations for it to share the knowledge with project managers and prevent such mistakes in the future.

The causes of budget overruns have been investigated by Bent Flyvbjerg and divided into four main groups [2] as follows:

1. Technical explanations (forecasting errors, price rises, inadequate planning procedures);

2. Economic explanations (underestimations due to lack of resources or incentives, poor financing or contract management);

3. Psychological explanations (optimism bias among local officials);

4. Political explanations (deliberate cost underestimation).

Mette K. Skamris Holm created a database of 258 large transport infrastructure projects, among which were 58 rail projects with an average cost overrun of $44.7 \%$, ranging from -46 to $+200 \%$. There were no significant differences between urban, high-speed and ordinary rail projects [3].

Cost overruns can also be due to some degree of uncertainty in initial cost estimates and forecasts. There are always extra costs caused by unexpected situations during project realization, e.g. natural disasters. We think it is possible to avoid mistakes in cost estimations and reduce the financial outcomes of ongoing and future large transportation projects, and railway projects in particular, by carrying out deep and detailed investigation of project costs in developed and experienced countries.

We consider cost benchmarking of railway projects in Europe to be a successful management tool for the current research because it has a clear structure and sequence.

Many international reports have used the benchmarking approach to compare some elements (e.g. unit, construction and maintenance costs) of high-speed railway projects.

The UIC made a report on the "The Cost of Railway Infrastructure" [1] in 2000 , in which they observed twelve railway projects from the EU, the US and Asia in order to find ranges of investment costs for building new high-speed or conventional rail projects or maintaining already-existing projects. They obtained some average values for major cost drivers which are relevant for railway infrastructure managers.

Similar research has been done by the private consulting company BSL for High-Speed Line 1(HS1) [4] in the United Kingdom; the line connects London with the Channel Tunnel and construction costs were EUR 6,670 million. They collected investment costs and relevant cost-driver values from six high-speed 
lines in four EU countries in order to be able to compare the costs position and important cost drivers of HS1 with other benchmarking participants. Some of these projects were considered in the present research.

\subsection{The focus of current research}

This paper describes on-going research focused on international benchmarking of high-speed railway projects and the knowledge obtained will be applied in the first high-speed railway line in Denmark - "New Line Copenhagen-Ringsted".

The goal of this railway project is to improve public transport by increasing the railway capacity between Copenhagen and Ringsted, reducing travel time and delays, and providing a high-quality railway transport service for travellers. The total line length is $56 \mathrm{~km}$ with an operating speed of $250 \mathrm{~km} / \mathrm{h}$. The current research is a great opportunity to learn from best practice elsewhere and get a "best-in-class" railway in 2018.

The above-mentioned literature sources were used as our starting point for research on a variety of other theoretical questions. They all have a clear structure and an emphasis on the information needed for different cost disciplines.

To enable a positive benchmarking contribution to current research, a database of high-speed railway projects was collected, including data on overall cost values, the number of physical components (tunnels, bridges, roads), contract types, and lists of consulting and contracting companies with recommendations from other infrastructure managers.

A number of relevant high-speed railway projects were visited to obtain practical collaboration with infrastructure managers. These included visits to construction sites to get a useful visual understanding of the project's size, quality and the technology used; there were face-to-face meetings with stakeholders and a review of the project's financial reports.

Furthermore, the breakdown of project's costs by disciplines and units was examined and compared with the Danish project. The disciplines were distributed by key performance indicators (e.g. price per $\mathrm{km}$ of road/rail, etc.) so as to set targets for future improvement.

The results presented in this paper are preliminary and represent an analysis of initial findings to allow the reader to understand the methodology and complexity of dealing with the cost disciplines and making unit cost comparisons between different railway projects.

\section{Methods}

The present research paper is based on previous experience, literature sources related to cost overruns in large transport projects around the world, and deviations in construction costs in specific high-speed railway projects (research carried out by various railway organizations and consultancy companies) [4-7]. But the research described here was more detailed and went deeper, because it 
investigated cost distribution across the different disciplines (tracks, railway technology, construction, administration, etc.) and their financial values.

To create a sample for further investigation, the performance and experience of various high-speed and conventional rail projects in Europe were examined, all comparable with the Copenhagen-Ringsted railway in terms of length, physical structure, alignment and other aspects suitable for comparison.

All the projects selected were benchmarked at three levels.

Firstly, many different railway projects in Europe were examined by searching data available in the literature, the Internet, and the experience of the consultancy company Grontmij $\mathrm{A} / \mathrm{S}$ and, based on our findings, we selected projects whose data were considered reliable for further comparison. This selection is presented in Table 1 and the main features of the projects examined are presented in Table 2 below.

Table 1: $\quad$ Review of the projects examined.

\begin{tabular}{|l|l|c|c|}
\hline \multirow{2}{*}{ Country } & \multicolumn{1}{|c|}{ Projects } & $\begin{array}{c}\text { Length, } \\
\text { km }\end{array}$ & $\begin{array}{c}\text { Cost B } \\
\text { EUR }\end{array}$ \\
\hline \multirow{3}{*}{ Belgium } & HSL 1 (Brussels-French border) & 88 & 1.42 \\
& HSL 2-3 (Brussels-Liege-German border) & 139 & 1.51 \\
& HSL 4 (Antwerp-Dutch border) & 87 & 1.57 \\
\hline \multirow{5}{*}{ France } & LGV Rhine-Rhone & 140 & 2.30 \\
& LGV Est européenne & 300 & 4.00 \\
& LGV Est européenne 2 ${ }^{\text {nd }}$ phase & 106 & 2.01 \\
& LGV South Europe Atlantic & 303 & 7.00 \\
& LGV Bretagne-Pays de la Loire & 180 & 3.40 \\
& LGV Méditerranée & 250 & 3.80 \\
\hline \multirow{4}{*}{ Germany } & HSL Cologne-Frankfurt & 177 & 6.00 \\
& HSL Nuremberg-Munich & 171 & 3.60 \\
& HSL Erfurt-Leipzig/Halle & 123 & 2.60 \\
\hline \multirow{3}{*}{ Italy } & HSL Rome-Naples & 205 & 5.77 \\
& HSL Turin-Milan & 125 & 7.70 \\
The & HSL Milan-Bologna & 182 & 6.91 \\
Netherlands & Hanzelijn (Zwolle-Lelystad) & 50 & 1.12 \\
& HSL Zuid (Amsterdam-Belgian border) & 125 & 7.19 \\
\hline Norway & Gardermoen Line (Oslo-Eidsvoll) & 64 & 1.00 \\
\hline Spain & HSL Madrid-French border & 803 & 13.20 \\
\hline \multirow{3}{*}{ Sweden } & BanaVäg i Väst (Göteborg-Trollhättan) & 75 & 1.05 \\
& Mälarbanan (Tomteboda-Barkaby-Kalhäll) & 20 & 1.16 \\
& Arlandabanan (Stockholm-Arlanda) & 19 & 0.65 \\
\hline The United & High Speed 1 (St Pancras - Channel Tunnel) & 109 & 6.67 \\
Kingdom & & & \\
\hline
\end{tabular}


Table 2: $\quad$ Main characteristics of the projects examined.

\begin{tabular}{|l|l|}
\hline Number of projects & 23 projects in 9 countries \\
\hline Observed projects & HSL and conventional railways \\
\hline Length & $19-803 \mathrm{~km}$ \\
\hline Traffic, \# tracks & Mixed and passenger, single and double \\
\hline Designed speed & $200-320 \mathrm{~km} / \mathrm{h}$ \\
\hline Physical requirements & $\begin{array}{l}\text { Flat terrain, allocation along the motorways, small } \\
\text { number of complex structures (tunnels) }\end{array}$ \\
\hline Overall budget & $654-13,200$ M EUR \\
\hline Value per km & $10.86-61.19$ M EUR/km \\
\hline Construction period & $1994-2025$ \\
\hline
\end{tabular}

The projects above were benchmarked at the top level, collecting all relevant data and forming the database and top-level comparison of construction costs per kilometre of the lines.

There were difficulties in getting information about exact construction costs, physical structures, etc., which is why the next step in benchmarking process was begun.

The second step was based on a questionnaire for infrastructure management and other engineering organizations responsible for project realization, e.g. the French company, Inexia, was responsible for LGV Rhin-Rhône, and the Belgian company, TUC Rail, was responsible for all Belgian HSL construction. The questionnaire consisted of four parts:

1. Project overview, i.e. all relevant data concerning planning and construction time, initial and final outcomes of particular projects, pricing year, and the agency responsible;

2. The project's physical structures, i.e. exact numbers of tunnels, bridges, viaducts and other relevant structures, and their geometric parameters (length, breadth, height);

3. Industry, i.e. contract types, names of companies that participated in the construction and planning;

4. Construction costs, i.e. deviation of construction cost in the different disciplines (tracks, power supply, telecommunication, signalling, administration, etc.). The budgeting model of Copenhagen-Ringsted project was put there as a template. This consists of 12 main cost disciplines. 
The third step was to make an initial internal benchmarking of the Copenhagen-Ringsted railway project, in which the main cost disciplines were distributed to Key Performance Indicators and analysed (e.g. the discipline "Tracks" was distributed to unit costs of rails, ballast, gravel, switches, etc.). Then they were sent to all participants as an example in order to obtain similar data from their projects.

All the data received through the questionnaire was analysed and is presented in this paper anonymously.

\section{Results}

The results of the first level of benchmarking are shown in Figure 1, where all the observed projects present their cost per $\mathrm{km}$. The average value for this sample is EUR 27 million. The last four projects have very high costs - due to several different factors, including project complexity, construction during existing railway operations, and reconstruction of neighbouring motorway. If these last four are not considered for further investigation, then the average value changes to EUR 21 million.

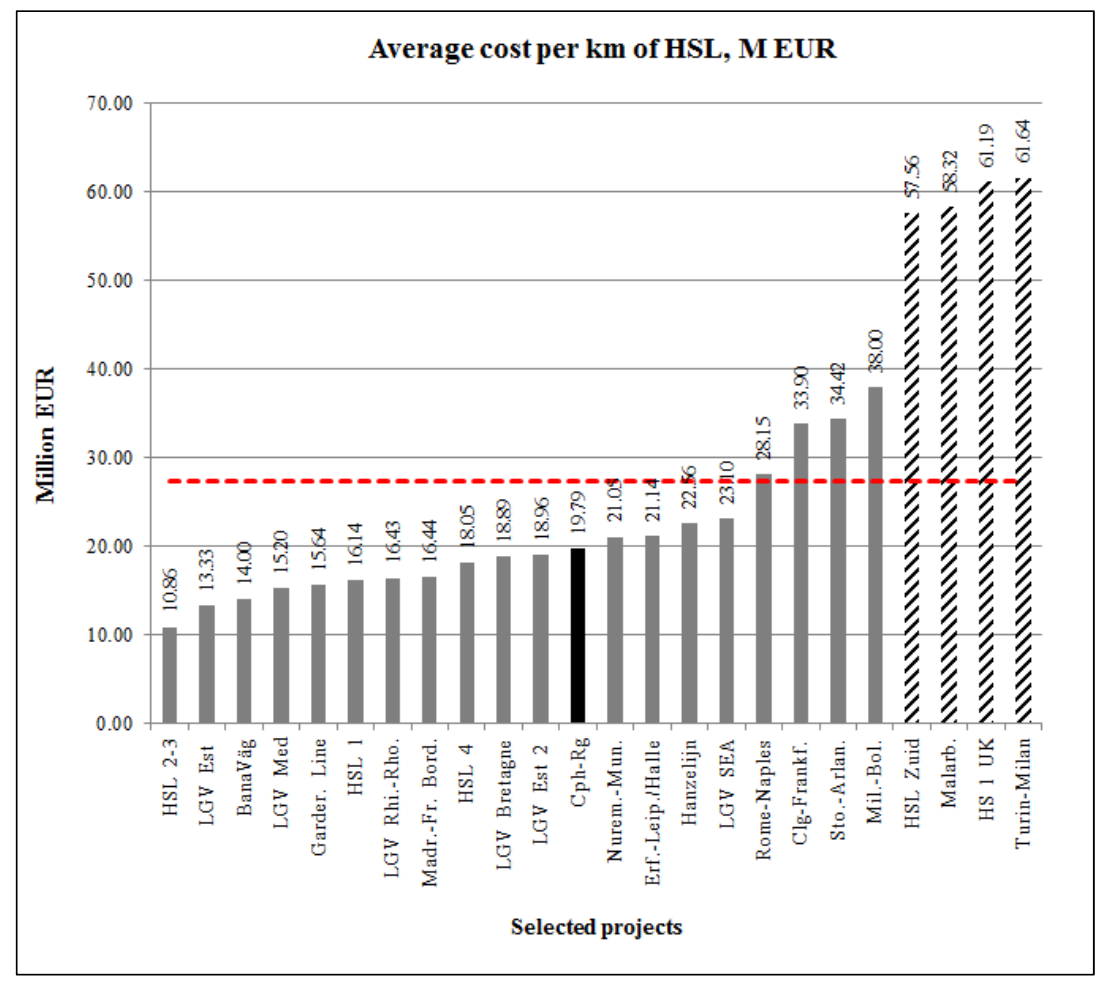

Figure 1: Average construction costs of new HSL (with a mean of EUR 27 mil). 
Further investigation and cost breakdowns were based on answers received from our questionnaire. The response from questionnaire recipients was $50 \%$. Five French and one Swedish project rejected participation for reasons of confidentiality; three German projects presented very basic data without any cost distribution for the same reason; two projects rejected participation without giving any reason. But the remaining projects provided sufficient information for further analysis, although in some cases breakdowns were not possible because the data supplied was insufficient for a particular comparison; e.g. the Dutch project Hanzelijn could not provide data for some cost positions because they have signed design-and-build contracts, so they did not have information for individual disciplines but only for the whole contract; the Belgian Infrabel project could only supply for making a distribution per main discipline after 2005 , because before that, another organization was involved.

All the participants tried to match the cost distribution model of CopenhagenRingsted project that we sent them. This was presented in pie form (as shown in Figure 2) and all recipients have provided matching data.

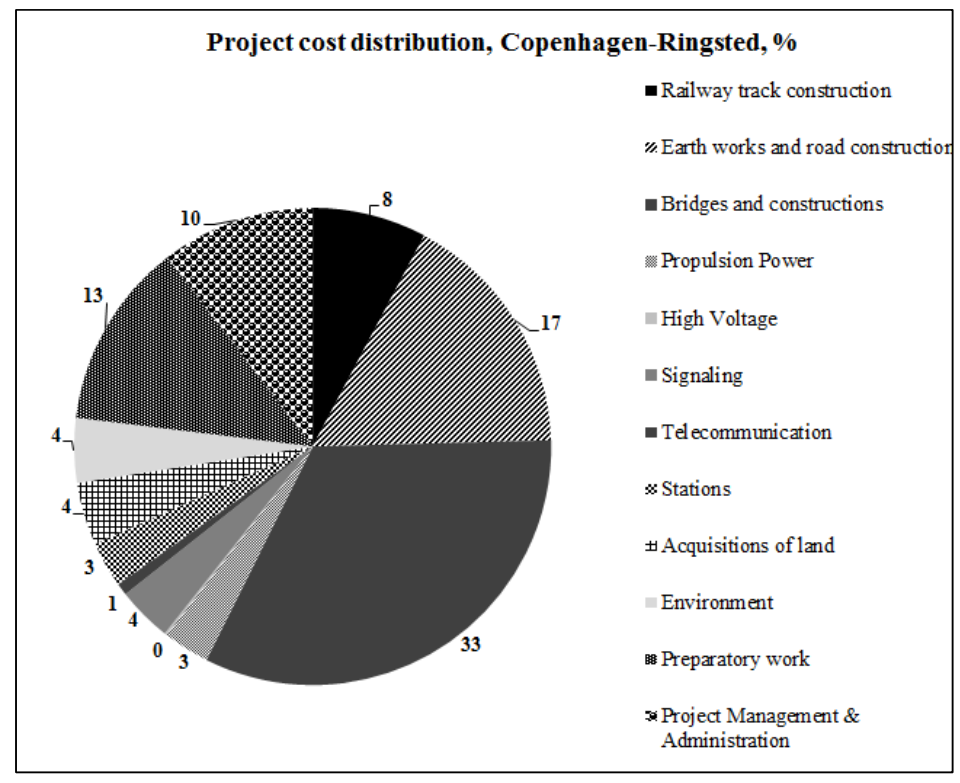

Figure 2: $\quad$ "The New Line Copenhagen-Ringsted" project budget, \%.

The data from other projects was collected and compared; the results are presented in Figure 3.

The above figure shows that the construction of railway tracks, structures (tunnels, bridges, etc.) and related earth works have the largest share in any cost distribution. 


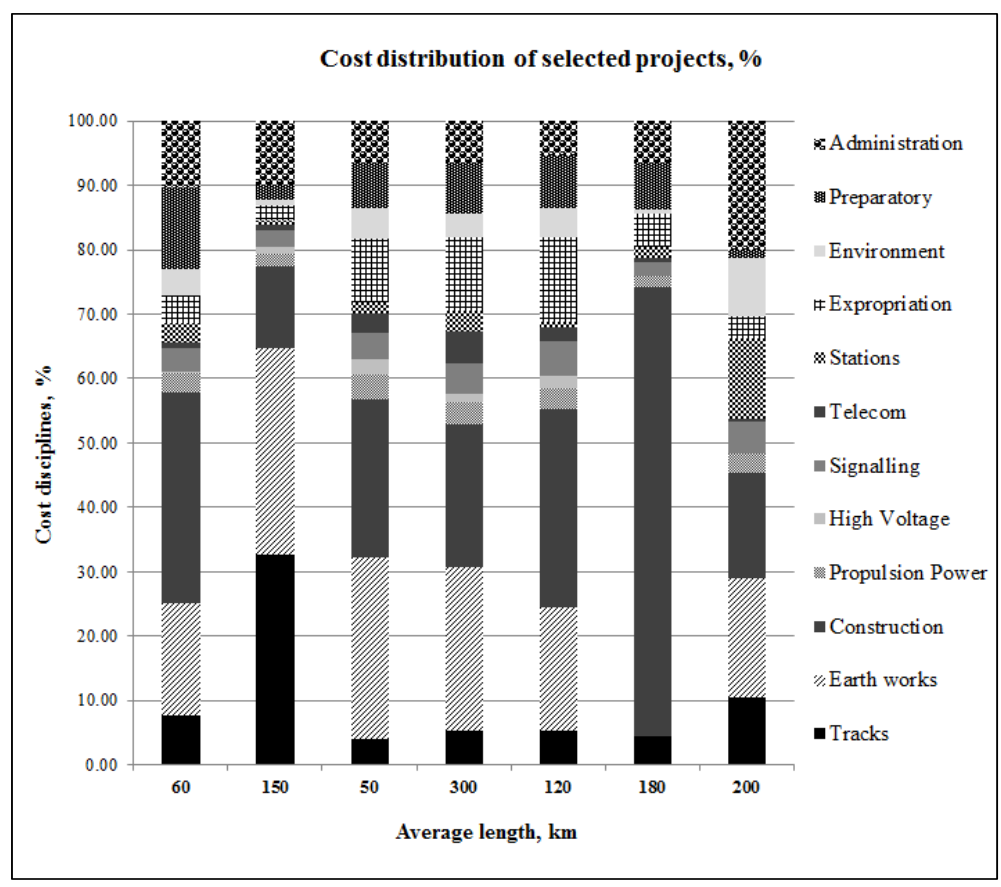

Figure 3: Distribution of costs in $\%$ from the available questionnaire data.

We then analysed the unit costs. Focus was on the units relevant for the Copenhagen-Ringsted project, which is not going to begin construction until the end of 2012. The data on earth works, structures and track alignment is currently vital. The unit costs were extracted from cost discipline data provided and compared on the basis of units per kilometre.

The results are shown in Figure 4 below (project " $A$ " is "The New Line Copenhagen-Ringsted").

The above graphs (a, b, c and d) show that the planned costs for the Copenhagen-Ringsted project are below the average value and quite a long way below the results from most of the other participants. But some figures are even lower than those of the Copenhagen-Ringsted project, which means that additional investigation and analysis is required to find out why. The focus must be on contract types, railway material producers, and average prices for these materials, because this also affects the final financial cost of a particular unit.

The industrial companies involved in the projects on the different phases were also analysed. It was clear that national and local contractors were preferred in all projects, because it is easy to maintain communication and legislation procedures between project managers and contractors. There were just a few well-known international companies, such as Balfour Beatty (UK), Alstom (France) and Ansaldo STS S.p.A. (Italy), involved in a few projects due to their huge experience in the installation of railway technology. 


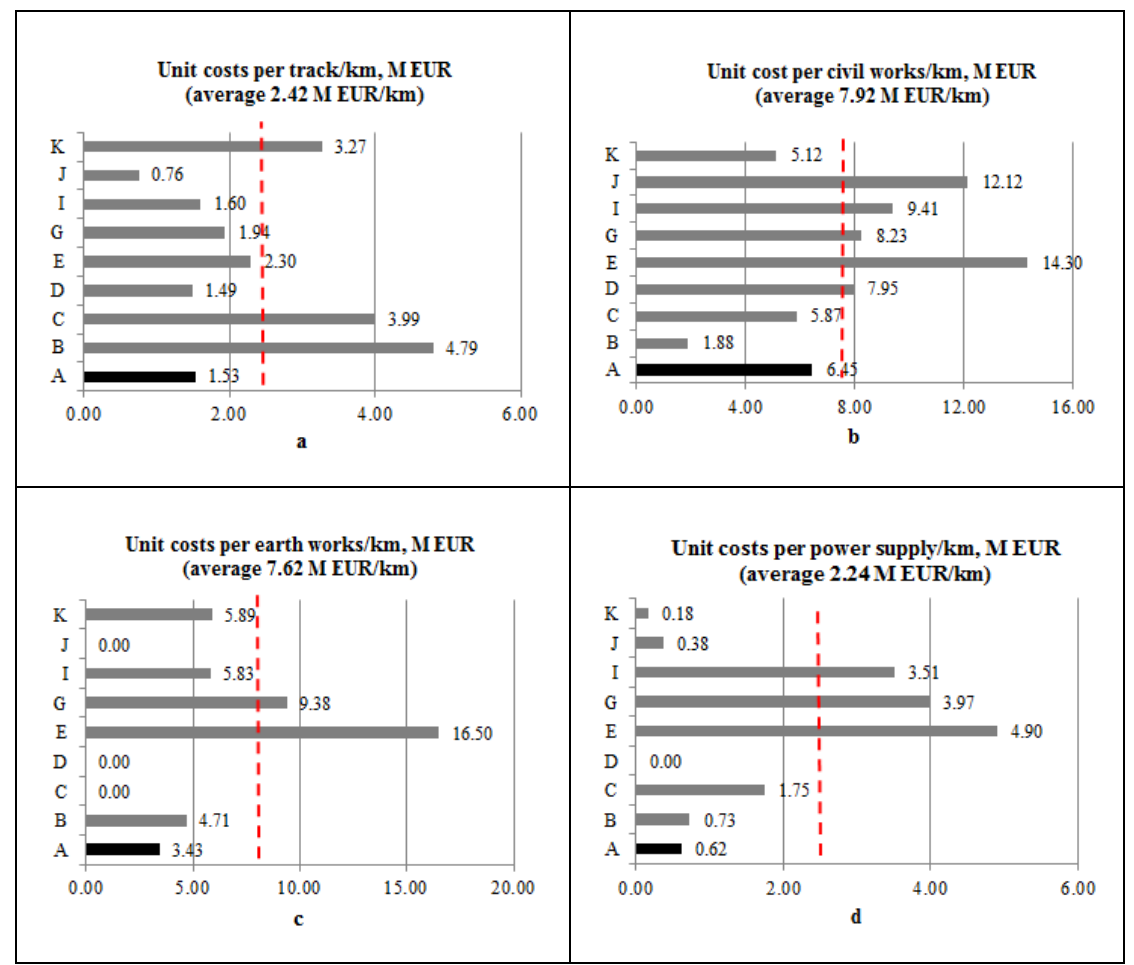

Figure 4: Unit costs per kilometre in the main disciplines for selected projects.

\section{Discussion}

The graphs in Figure 4 show the relevant unit costs for the main cost drivers from selected projects. The values are very different and we have discussed some of the factors that affect these main costs. Bridges and tunnels, construction in urban areas, the design speed, and traffic interference are the most significant cost drivers in any project [1]. Planning and realization time bring additional costs to any project, especially when the planned schedule is exceeded by a certain percentage. All these unit cost values need to be analysed in detail, e.g. by distributing structures across the complexity groups (large, middle and small constructions) and finding unit costs per square metre for bridges and viaducts.

Moreover, it is also important to check economy-of-scale effects in completed projects, i.e. whether there were significant financial differences in the quantity of structures constructed by one of more contractors.

Our findings and analysis will bring additional knowledge to other Infrastructure Managers in terms of cost distribution in large-scale projects. They will be able to make their own internal benchmarking and compare it with results of current research in order to define particular cost positions which they can 
afterwards minimize to some extent, e.g. by establishing competition between material suppliers.

\section{Preliminary conclusion}

The preliminary results of this on-going research show the rough values of unit costs for various cost disciplines. The range of unit costs has a big spread in each particular comparison, as seen in Figure 4 This may be explained by different components being included in a particular discipline, e.g. these depend on the level of cost breakdown provided by participants and also on the complexity of each project and the country's technical and construction standards [4].

"The New Line Copenhagen-Ringsted" demonstrates good cost values in comparison with other projects. However, additional analysis is required of the projects with lower costs to understand their successful results and learn from their experience.

Additional detailed analysis of unit costs will be carried out to find the costs for main structures expressed in EUR per square/cubic meter.

The industry review based on questionnaire answers shows that collaboration with national industrial companies is preferable, but because Denmark is a small country and has a small construction market, we assume that lower prices have been achieved by establishing competition between local and international contractors.

\section{References}

[1] BSL Management, The Cost of Railway Infrastructure, 2000.

[2] Flyvbjerg, B., Skamris Holm, M.K., and Buhl, S.L., What Causes Cost Overrun in Transport Infrastructure Projects? Transport Reviews, Vol. 24, No. 1, 3-18, January 2004.

[3] Skamris Holm, M.K., Economic Appraisal of Large Scale Transport Infrastructure Investments, a $\mathrm{PhD}$ thesis submitted to Aalborg University, December 2000.

[4] BSL Management Consultants GmbH \& Co. KG, Comparison of High Speed Lines' CAPEX, Final report, Hamburg, November 2009.

[5] Campos, J., de Rus, G., Barrón, I., Some stylized facts about high speed rail around the world: an empirical approach, 4th Annual Conference on Railroad Industry Structure, Competition and Investment, Universidad Carlos III de Madrid, October 19-21, 2006.

[6] Steer Davies Gleave, High Speed Rail: International Comparisons, Final Report, February 2004.

[7] Hertogh, M., Baker, S., Staal-Ong., P.L., and Westerveld, E., Managing Large Infrastructure Projects, Research on Best Practices and Lessons Learnt in Large Infrastructure Projects in Europe, 2008. 